\title{
A center of excellence displays its wares: How does your mitral practice stack up?
}

\author{
David D. Yuh, MD, FACS, FACC
}

From the Department of Surgery, Stamford Hospital, Stamford, Conn.

Disclosures: Author has nothing to disclose with regard to commercial support.

Received for publication March 4, 2018; accepted for publication March 8, 2018; available ahead of print April 3, 2018

Address for reprints: David D. Yuh, MD, FACS, FACC, Department of Surgery, Stamford Hospital, One Hospital Plaza, PO Box 9317, Stamford, CT 06904 (E-mail: DYuh@stamhealth.org).

J Thorac Cardiovasc Surg 2018;156:130-1

$0022-5223 / \$ 36.00$

Copyright $(c) 2018$ by The American Association for Thoracic Surgery

https://doi.org/10.1016/j.jtcvs.2018.03.029

In their article in this issue of the Journal, Javadikasgari and colleagues ${ }^{1}$ provide valuable data reflecting contemporary practice and outcomes with respect to mitral repair. Current indications and guidelines for the elective repair of degenerative mitral disease have pivoted toward earlier intervention, before the onset of symptoms or structural changes in ventricular dimensions and function. The conundrum facing many surgeons, however, lies in the fact that this more aggressive stance is predicated on the conditions that "the likelihood of a successful and durable repair without residual mitral regurgitation is greater than $95 \%$, with an expected mortality rate of less than $1 \%$ when performed at a Heart Valve Center of Excellence." 2 Earnestly meeting these conditions with variegated presentations of degenerative mitral disease, contemporary, ever-evolving repair techniques, and sporadic echocardiographic follow-up would require clairvoyance beyond even experienced mitral surgeons; it seems akin to achieving a 95\% success rate and sub $1 \%$ mortality in reaching my office on time each morning with the backdrop of New York City traffic and train schedules.

At the very least, however, this study proves that such metrics are achievable, albeit under ideal circumstances in an experienced and successful heart valve center. Welldesigned, adequately powered analyses providing convincing data reflecting outcomes for current state-ofthe-art mitral repair have heretofore been lacking. Javadikasgari and colleagues ${ }^{1}$ have addressed this void by providing repair success rates, longitudinal durability, and survival data across different mitral pathologies and contemporary repair techniques against which mitral surgeons can compare and evaluate their own capabilities (and limitations). From a practical standpoint, this study provides surgeons with citable data to answer the question often asked by patients: "How long will my repair last?" Moreover, the prospect of catheter-based technologies rendering bioprosthetic valve replacement as a life-long solution (eg, valve-in-valve) or competing with surgical repair altogether may introduce uncertainty among patients with complex disease weighing different options.

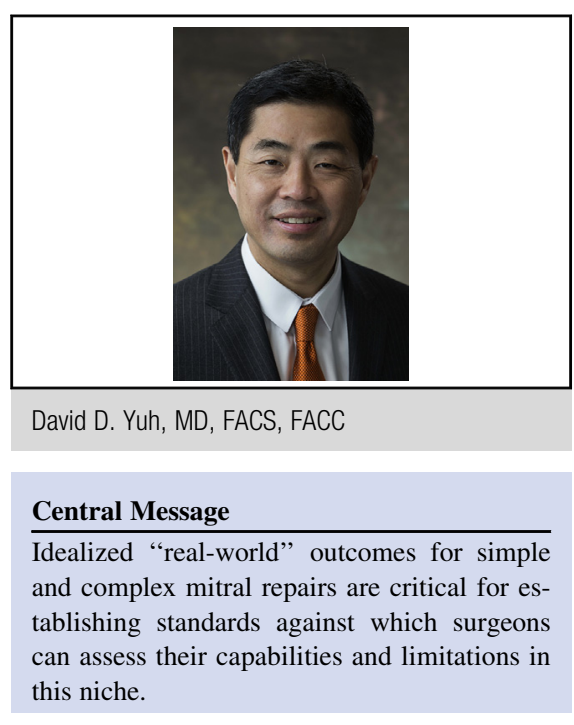

See Article page 122

One of this study's strongest features is its partitioning of outcomes between "simple" and "complex" mitral pathologies. Although the mode of differentiation, which was based on posterior versus anterior leaflet pathologies, is somewhat artificial (eg, not all P2 prolapses are created equal), it provides useful benchmark data for surgeons who do not have high-volume mitral practices yet feel comfortable with and adept at straightforward posterior leaflet repairs. Previous studies have examined and effectively validated the impact of individual surgeon volume and surgical center on both the likelihood of performing mitral repairs and success rates ${ }^{3,4}$; however, the impact of repair complexity has not been well examined until now.

Finally, the association of artificial neochords with recurrent mitral regurgitation may raise concern, particularly among surgeons who favor less-invasive surgical approaches and subscribe to the "respect, not resect" philosophy. This finding should prompt further investigation as to whether the causes behind it are related to valve pathology or technique.

Despite the inherent limitations of a nonrandomized study with unavoidable limitations in longitudinal echocardiographic follow-up, Javadikasgari and colleagues ${ }^{1}$ provide important insight into the evolution of mitral repair practice during a critical period, contemporary "real world" repair outcomes achievable with experience and 
setting, and granularity that may prompt further investigation into technique selection for particular pathologies.

\section{References}

1. Javadikasgari H, Mihaljevic T, Suri RM, Svensson LG, Navia JL, Wang RZ, et al. Simple versus complex degenerative mitral valve disease. J Thorac Cardiovasc Surg. 2018;156:122-9.e16.

2. Nishimura RA, Otto CM, Bonow RO, Carabello BA, Erwin JP III, Fleisher LA, et al. 2017 AHA/ACC focused update of the 2014 AHA/ACC guideline for the management of patients with valvular heart disease: a report of the American College of Cardiology/American Heart Association task force on clinical practice guidelines. J Am Coll Cardiol. 2017;70:252-89.

3. Chikwwe J, Toyoda N, Anyanwu AC, Itagaki S, Egorova NN, Boateng P, et al. Relation of mitral valve surgery volume to repair rate, durability, and survival. J Am Coll Cardiol. 2017:69:2397-406.

4. Kilic A, Shah AS, Conte JV, Baumgartner WA, Yuh DD. Operative outcomes in mitral valve surgery: combined effect of surgeon and hospital volume in a population-based analysis. J Thorac Cardiovasc Surg. 2013; 146:638-46. 